Bond University

Research Repository

\title{
Alexithymia, Fear of Intimacy, and Relationship Satisfaction
}

Lyvers, Michael; Pickett, Louisa; Needham, Katarina; Thorberg, Fred Arne

Published in:

Journal of Family Issues

DOI:

10.1177/0192513X211010206

Licence:

Other

Link to output in Bond University research repository.

Recommended citation(APA):

Lyvers, M., Pickett, L., Needham, K., \& Thorberg, F. A. (2022). Alexithymia, Fear of Intimacy, and Relationship Satisfaction. Journal of Family Issues, 43(4), 1068-1089. https://doi.org/10.1177/0192513X211010206

\footnotetext{
General rights

Copyright and moral rights for the publications made accessible in the public portal are retained by the authors and/or other copyright owners and it is a condition of accessing publications that users recognise and abide by the legal requirements associated with these rights.
}

For more information, or if you believe that this document breaches copyright, please contact the Bond University research repository coordinator. 
Alexithymia, Fear of Intimacy, and Relationship Satisfaction 


\begin{abstract}
Alexithymia, fear of intimacy, attachment security, and mood variables were examined as predictors of satisfaction in couple relationships after accounting for age, sex, relationship length, and marital status. Participants were 158 adults (52\% women, $48 \%$ men) in an ongoing couple relationship for 1-19 years. They completed validated measures of the variables of interest online. Bivariate correlations were significant for all predicted associations. Multiple mediation modelling examined the hypothesis that the low relationship satisfaction reported by those with alexithymia can be explained by fear of intimacy, insecure attachment, and negative affect, after accounting for relevant covariates. Mediation was indicated for fear of intimacy and negative affect. Such factors may merit particular attention by clinicians working with alexithymic clients in couples therapy.
\end{abstract} Key words: relationships; personality; alexithymia; couples 
The physical and mental health benefits of sustained, satisfying couple relationships are well documented. Relationship satisfaction has been linked to lower blood pressure, lower mortality rates, better immune function, and higher levels of happiness, life satisfaction, and affective wellbeing (De Andrade, Wachelke, \& HowatRodrigues, 2015; Kiecolt-Glaser \& Newton, 2001), and acts as a buffer against emotional distress (Rosand, Slinning, Eberhard-Gran, Roysamb, \& Tambs, 2012). The aim of the present study was to fill a gap in understanding of the association of a personality trait, alexithymia, with low levels of satisfaction in couples, as detailed below. Understanding the role of alexithymia in relationship dissatisfaction could potentially inform clinician approaches to couples therapy.

In the present context, relationship satisfaction refers to a person's subjective evaluation of the quality of their ongoing couple relationship (Keizer, 2014). Among a number of factors purported to influence such evaluations are personality variables. Traits such as agreeableness and conscientiousness are reported to promote relationship satisfaction (Fincham, 2001; Gerlach, Driebe, \& Reinhard, 2018; Schaffhuser, Allemand, \& Martin, 2014). By contrast, neuroticism and alexithymia, as well as factors often linked to those traits such as fear of intimacy (Thelen, Vander Wal, Thomas, \& Harmon, 2000), an insecure attachment style (Kimmes, Durtschi, Clifford, Knapp, \& Fincham, 2015), and negative moods (Brock, Franz, O'Bleness, \& Lawrence, 2018), are negatively related to relationship satisfaction (Humphreys, Wood \& Parker, 2009). The association between negative mood and relationship satisfaction is reportedly bidirectional (Brock et al., 2018), such that depression predicts worsening relationship satisfaction over time and vice-versa. The crucial roles of emotional intimacy (Patrick, Sells, Giordano \& Tollerud, 2007; Yoo, Bartle-Haring, Day \& Gangamma, 2014) and attachment security (Vollmann, Sprang \& van den Brink, 2019) in relationship satisfaction have long been recognized. More recent 
work has indicated that the personality trait alexithymia is associated with low relationship satisfaction (Besharat et al., 2014; Humphreys et al., 2009; Karakis \& Levant, 2012), however the basis of this is not clear.

Alexithymia is a subclinical personality dimension defined by difficulties identifying and describing feelings as well as an externally oriented cognitive style (Luminet, Bagby \& Taylor, 2018). Although varying on a continuum, high alexithymia as defined by established cut-off score on the Toronto Alexithymia Scale 20 (TAS-20; Bagby, Taylor \& Parker, 1994) has an estimated population prevalence of 10-15\% (Mattila, Salminen, Nummi \& Joukamaa, 2006; Salminen, Saarijärvi, Äärelä, Toikka \& Kauhanen, 1999). In Australia, high alexithymia was reported to have a prevalence of $46 \%$ in psychiatric samples versus $12 \%$ in community samples (McGillivray, Becerra \& Harms, 2016). An insecure (anxious/avoidant) attachment style (Besharat, Naghshineh, Ganji, \& Tavalaeyan, 2014; Karakis \& Levant, 2012) as well as fear of intimacy (Besharat et al.; Lyvers, Davis, Edwards \& Thorberg, 2017) and persistent negative moods such as depression, anxiety and stress (Thorberg, Young, Sullivan \& Lyvers, 2009) have all been reported to be positively associated with alexithymia. The present study thus sought to assess whether the low relationship satisfaction associated with alexithymia might be explained by insecure attachment, fear of intimacy, and/or negative mood, i.e., potentially relevant factors that have been linked to alexithymia in previous work.

Alexithymic individuals typically have problems with emotional self-regulation, and show deficient ability to correctly identify and empathize with the emotions of others (Lyvers, Kohlsdorf, Edwards \& Thorberg, 2017; Prkachin, Casey, \& Prkachin, 2009; Taylor \& Bagby, 2004). Given the importance of emotional awareness, communication, and empathy in sustaining close relationships (De Andrade et al., 2015; Olson \& Olson, 1999; Overall, Fletcher, Simpson, \& Sibley, 2009; Vanglelisti, Reis, \& Fitzpatrick, 2002), 
reports of loneliness and persistent interpersonal difficulties in those with alexithymia (Besharat et al., 2014; Qualter, Quinton, Wagner, \& Brown, 2009; Spitzer, Siebel-Jurges, Barnow, Grabe, \& Freyberger, 2005) are thus not surprising. Heritability of alexithymia is reportedly only 30-33\% (Jorgensen, Zachariae, Skytthe, \& Kyvik, 2007), hence developmental influences likely play a significant role. Drawing from Bowlby’s (1988) attachment theory as applied to adult attachment styles (Mikulincer, Shaver \& Pereg, 2003), Lyvers et al. (2019) postulated that inadequate bonding with the primary caregiver in childhood delays or prevents normal acquisition of emotional self-knowledge and selfregulation skills, leading to difficulties in forming stable relationships with peers. The resultant experiences of rejection and other interpersonal problems are likely to eventuate in an insecure attachment style that persists in adulthood.

Adult attachment style, which is reportedly stable over time (Zhang \& LabouvieVief, 2004), appears to play a fundamental role in satisfaction with intimate relationships (Butzer \& Campbell, 2008; Kimmes et al., 2015; Mikulincer \& Shaver, 2007).

Alexithymia has been associated with an insecure (anxious/avoidant) adult attachment style (Besharat et al., 2014; Thorberg et al., 2011b), characterized by lack of trust in a partner, anxiety over the prospect of abandonment, and a reluctance to share personal concerns, as well as expressed discomfort at the prospect of emotional closeness, often referred to as fear of intimacy (Thelen et al., 2000). Given that proneness to negative moods, insecure attachment, and fear of intimacy have all been linked to alexithymia, the present study examined these variables as potential mediators of the low relationship satisfaction associated with alexithymia among adults in long-term couple relationships.

Alexithymia was treated as a continuous trait variable in the present study and was operationally defined by scores on the widely used Toronto Alexithymia Scale 20 (TAS20; Bagby, Parker \& Taylor, 1994). Although a self-report measure might seem a dubious 
means of assessing levels of a trait defined by difficulties with some aspects of introspection, research has shown convergence between TAS-20 and clinician ratings of alexithymia (Thorberg et al., 2010). Further, TAS-20 scores have been shown to negatively predict performance on tests of emotion recognition (Lyvers, McCann, Coundouris, Edwards, \& Thorberg, 2018), further supporting the validity of this selfreport measure. Based on evidence described earlier, the negative association of alexithymia with satisfaction in long-term couple relationships was hypothesized to reflect the influences of three variables that were linked to alexithymia in previous research, i.e., insecure attachment, fear of intimacy, and frequent or persistent negative affect. Potential influences of other factors that reportedly covary with relationship satisfaction, including age, sex (Jackson, Miller, Oka, \& Henry, 2014; Kamp Dush, Taylor \& Kroeger, 2008), relationship length (Glenn, 1998; Keizer, 2014), and marital status, were assessed as covariates. Relationship satisfaction was expected to show negative associations with alexithymia, fear of intimacy, insecure attachment, and negative mood. Mediation modelling was predicted to show that after controlling for covariates, the association of alexithymia with low relationship satisfaction would be mediated by insecure attachment, fear of intimacy, and negative mood, all of which have been linked to alexithymia in other work cited earlier.

\section{Method}

\section{Participants}

Participants were recruited from the general Australian population online via the internet-based survey tool Qualtrics Panels, which allows a targeted population to be sampled. The research was advertised as a study of factors associated with satisfaction in long term romantic relationships among people aged 18-40 years, who are currently in an ongoing couple relationship that has lasted for more than six months. Only one member of 
such couples was requested to participate in the study to avoid complications that could arise from some couples completing the measures together. There were 166 individuals who initially took part in the study; 2 cases were subsequently removed due to missing data, and 6 cases were removed as multivariate outliers identified by Mahalanobis distance $(p<.001)$. This yielded a final sample of 158 participants, which was more than sufficient to detect a medium sized effect for 10 predictors (Tabachnick \& Fidell, 2013). Of this sample of adults aged 22-40 years $(M=28.84, S D=6.43), 76$ participants identified as men (48\%) and 82 participants identified as women (52\%). All participants reported being in a current romantic relationship that had been ongoing for 1 to 19 years $(M=5.53 ; S D=$ 4.48) prior to the study. There were 76 participants (48\%) who indicated they were married or engaged to their partner, versus $82(52 \%)$ who indicated they were not. Education levels varied in the sample in line with recent population data reported by the Australian Bureau of Statistics (2018), such that 34 participants (21.5\%) reported high school as their highest level of completed education, 34 participants $(21.5 \%)$ had completed a trade school course, 53 participants $(33.5 \%)$ had a Bachelor degree, 17 participants $(10.8 \%)$ had a postgraduate diploma, 15 participants (9.5\%) had a Master degree, and a $\mathrm{PhD}$ was reported by 5 participants (3.2\%). The majority of participants were born in Australia (104, 65.8\%); of the remainder, $11(7 \%)$ were born in India, 8 (5.1\%) were born in the Philippines, 26 (16.4\%) reported various other countries of birth, and $9(5.7 \%)$ did not specify where they were born.

\section{Measures}

Demographics Questionnaire. A brief self-report demographics questionnaire was presented at the start of the online questionnaire battery to obtain information on participant age, sex, country of birth, education level, relationship status (married/engaged or not), and length of current relationship. 
Couples Satisfaction Index (CSI; Funk \& Rogge, 2007). The CSI consisted of 32 self-report items assessing relationship satisfaction. Responses were made via six-point Likert scales with options from 0 to 5 , and a seven-point scale for one global item with options from 0 to 6; anchor labels varied depending on the item (e.g., "I still feel a strong connection with my partner" had six response options from 0 not at all true to 5 completely true). Summation of item responses yielded a total relationship satisfaction score, with higher scores indicating greater relationship satisfaction. The CSI has demonstrated validity via robust correlations with other indices of relationship satisfaction (Funk \& Rogge, 2007). Internal consistency reliability of the CSI was adequate in the present sample $(\alpha=.73)$.

Toronto Alexithymia Scale (TAS-20; Bagby, Parker, \& Taylor, 1994). The TAS-20 was a 20-item self-report measure encompassing the three facets of alexithymia, difficulty identifying feelings (seven items; e.g., "I have feelings that I can’t quite identify"), difficulty describing feelings (five items; e.g., "It is difficult for me to reveal my innermost feelings, even to close friends"), and externally oriented thinking (eight items; e.g., "I prefer to watch 'light' entertainment shows rather than psychological dramas"). Items were rated on a five-point Likert scale ranging from 1 (strongly disagree) to 5 (strongly agree), with five items reverse scored; item responses were summed to yield a total score such that higher scores indicated higher levels of alexithymia. Psychometric studies have generally supported the reliability and validity of the TAS-20 (Sekely, Bagby \& Porcelli, 2018; Thorberg et al., 2010). Convergent validity of the TAS-20 was indicated by expected correlations with other alexithymia measures including the Bermond-Vorst Alexithymia Questionnaire (Zech, Luminet, Rime \& Wagner, 1999) and the Toronto Structured Interview for Alexithymia (Bagby, Taylor, Parker \& Dickens, 2006). Alternative models of alexithymia have also been offered (Preece, Becerra, Robinson, \& 
Dandy, 2017). Research by Gignac, Palmer and Stough (2007) supported a five-factor model of the TAS-20, although their interpretation has been disputed (Bagby, Taylor, Quilty \& Parker, 2007). Meganck, Vanheule and Desmet (2008) subsequently found further support for the three-factor model. The total TAS-20 score was utilized in this study as recommended by the authors of the original measure (see Sekely et al., 2018) and to ensure that the present results would be comparable to previous relevant research. The alpha index for the total TAS-20 was high in the present sample $(\alpha=.86)$.

Revised Adult Attachment Scale (RAAS; Collins, 1996). The RAAS, a revision of the original Adult Attachment Scale (AAS; Collins \& Read, 1990), consisted of 18 items assessing aspects of interpersonal attachment in adulthood. Items were rated on a five-point Likert scale ranging from $1=$ not at all characteristic of me to $5=$ very characteristic of me. There were three subscales of six items each: Close, Depend, and Anxiety. The Close scale assessed how comfortable the respondent is with closeness and intimacy (e.g., "I am comfortable developing close relationships with others"); the Depend scale assessed how comfortable the respondent is with depending on others (e.g., "I know that people will be there when I need them"); and the Anxiety scale assessed concerns about being rejected, unloved or abandoned (e.g., "I often worry that romantic partners won't want to stay with me"). Seven items were reverse scored. The respondent's mean rating on each subscale indicated the level of the corresponding attachment dimension. High scores on Close and Depend, and low scores on Anxiety, indicated a secure attachment style, whereas the opposite pattern indicated insecure attachment (Collins, 1996). Previous work has supported the reliability and validity of the RAAS (Brennan, Clark, \& Shaver, 1998). Attachment security as defined by the RAAS was found to be predictive of therapeutic relations when administered to psychotherapy patients (Goldman \& Anderson, 2007). Validity of the RAAS was further supported by expected associations 
with self-reported interpretations and perceived impacts of relationship events (Collins, 1996). In the present sample, internal consistency reliability was marginal for Close ( $\alpha=$ $.65)$, adequate for Depend $(\alpha=.74)$, and excellent for Anxiety $(\alpha=.90)$.

Fear of Intimacy Scale (FIS; Descutner \& Thelen, 1991). The FIS was a 35-item self-report measure of fear of intimacy in romantic relationships. A five-point Likert scale, ranging from $1=$ not at all characteristic of me to $5=$ extremely characteristic of me, was used to rate statements such as "I would feel comfortable expressing my true feelings to $\mathrm{O}$," where "O" represents the other person in a romantic relationship. The 30 items in Part A referred to the current close romantic relationship, whereas the 5 items in Part B were more general (e.g., "I have shied away from opportunities to be close to someone"). Fifteen items were reverse scored; summation of item responses then yielded a total score, such that higher scores indicated greater fear of intimacy. A single-factor solution and high testretest reliability have been reported for the FIS (Doi \& Thelen, 1993). Validity was supported by significant correlations in expected directions with measures of loneliness, self-disclosure, social intimacy, relationship duration and therapist ratings of fear of intimacy (Descutner \& Thelen, 1991). The FIS showed high internal consistency reliability in the current sample $(\alpha=.92)$.

Depression Anxiety Stress Scales 21 (DASS-21: Lovibond \& Lovibond, 1995).

The DASS-21 was a 21-item self-report index of negative moods experienced over the past week. There were three subscales consisting of seven items each: Depression (e.g., "I couldn't seem to experience any positive feelings at all"), Anxiety (e.g., "I felt I was close to panic"), and Stress (e.g., "I felt that I was using a lot of nervous energy"). Items were rated on a four-point Likert scale ranging from 0 (did not apply to me at all) to 3 (applied to me very much or most of the time). A total score for each scale was obtained by doubling the sum of item responses to make scores comparable to the 42-item version of the DASS. 
For the purposes of the current study, scale scores were combined to provide an overall index of negative affect such that higher scores indicated more negative mood symptoms experienced over the past week. The psychometric properties of the DASS-21 are reportedly excellent (Antony, Bieling, Cox, Enns, \& Swinson, 1998; Brown, Chorpita, Korotitsch, \& Barlow, 1997). Validity was supported by correlations of .72 to .85 with other measures of depression and anxiety (Antony et al, 1998). In the present sample, the internal consistency reliability of the total DASS-21 was very high $(\alpha=.97)$.

\section{Procedure}

The university ethics committee granted formal approval of the current study prior to data collection. Participants who met the inclusion criteria were recruited from the general Australian community online by Qualtrics. The specified parameters were Australians aged 18-40 years who are currently in a relationship that has been ongoing for at least 6 months, with an equal split of males and females. Those who wished to participate accessed the link provided, and read an explanatory statement outlining the purpose and nature of the study. The rights of participants were explained, including the voluntary and anonymous nature of participation; ticking a box at the bottom of the page indicated informed consent. The demographics questionnaire was completed first, followed by the other instruments presented in a uniquely randomized order for each participant. Completion of the questionnaire battery took approximately 35 minutes, after which Qualtrics provided a points-based incentive.

\section{Analysis Plan}

Planned analyses included preliminary comparison of men and women on the variables of interest, calculation of correlations among continuous measures, and multiple mediation modelling to test the hypothesis that the predicted negative relationship between alexithymia and relationship satisfaction would be explained by fear of intimacy, insecure 
attachment, and negative affect, after controlling for age, sex, and relationship type and length.

\section{Results}

\section{Preliminary Analyses}

Means, standard deviations, and ranges of values on the continuous variables are shown in Table 1. To test for sex differences in the sample, a one-way multivariate analysis of variance (MANOVA) compared men and women on CSI, TAS-20, RAAS (Close, Depend, Anxiety), DASS-21, and FIS scores as well as relationship length. The multivariate effect of sex was significant according to Pillai's Trace, $F(8,149)=3.68, p=.001$. Univariate sex differences were significant only for the RAAS attachment dimensions, with men indicating more secure attachment styles than women as indicated by men's significantly higher scores on Close and Depend, and lower scores on Anxiety, compared to women. Men $(M=3.30, S D$ $=.08)$ scored higher than women $(M=3.07, S D=.08)$ on RAAS-Close, $F(1,156)=4.09, p=$ .045. Men $(M=3.04, S D=.09)$ also scored higher than women $(M=2.54, S D=.08)$ on RAAS-Depend, $F(1,156)=16.88, p<.0001$. Women $(M=3.43, S D=.11)$ scored higher than men $(M=2.93, S D=.11)$ on RAAS-Anxiety, $F(1,156)=10.48, p=.001$. Men and women also differed on whether they categorized their current relationship of more than six months as married/engaged or not; proportionally more women in the sample indicated they were married or engaged (57\%) compared to men $(38 \%), \chi^{2}(1)=5.80, p=.02$.

Bivariate correlations among the continuous variables are shown in Table 2. The CSI measure of relationship satisfaction was significantly positively correlated with the RAAS attachment dimensions Close and Depend, whereas CSI was significantly negatively correlated with RAAS-Anxiety, TAS-20 alexithymia, the FIS measure of fear of intimacy, and the DASS-21 negative mood index, all as per expectations. Additional significant, expected correlations are also evident in Table 2. TAS-20 was negatively correlated with 
RAAS-Close and RAAS-Depend, and was positively correlated with RAAS-Anxiety, FIS, and DASS-21. RAAS-Anxiety was positively correlated with FIS and DASS-21. Correlations among the variables of interest were medium to large (Cohen, 1992; Ferguson, 2009) with the exception of the small (though significant) correlation between CSI and RAAS-Depend. The CSI index of relationship satisfaction - the criterion variable of interest - was not correlated with age or relationship length in the present sample, and did not differ by sex as mentioned earlier. Perhaps surprisingly, CSI scores also did not differ by relationship type $($ married/engaged or not $), t(156)=.27$.

\section{Multiple Mediation Analysis}

In JASP 0.14.1, multiple mediation modelling was conducted using bootstrapping with 1000 bias-corrected replications to test the hypothesis that the negative relationship between alexithymia and relationship satisfaction could be explained by fear of intimacy, insecure attachment, and negative mood, after controlling for age, sex, and relationship type and length. The predictor variable was entered as alexithymia, and the outcome variable as relationship satisfaction. Mediator variables were concurrently entered as negative mood, fear of intimacy, and the three RAAS attachment dimensions Close, Depend, and Anxiety. Although as noted none of the covariates (age, sex, type of relationship, and length of relationship) were associated with relationship satisfaction in the present sample, some previous studies cited earlier had indicated such associations, hence their potential influences were controlled. As can be seen in Table 3, the 95\% confidence intervals for the indirect effects of alexithymia through negative mood and fear of intimacy did not include zero and were thus significant, whereas there were no significant indirect effects through any of the attachment dimensions. The $95 \%$ confidence interval for the direct effect of alexithymia did include zero and was thus nonsignificant. The model as depicted in Figure 1 indicated full mediation. That is, people who reported higher levels of alexithymic characteristics also 
reported greater fear of intimacy in relationships and more frequent negative affect, and this fully explained the negative association of alexithymia with relationship satisfaction in the present sample.

\section{Discussion}

Despite the expected negative correlations of alexithymia scores with relationship satisfaction and the RAAS secure attachment dimensions Close and Depend, and the expected positive correlation of alexithymia with the RAAS insecure attachment dimension Anxiety, multiple mediation modelling indicated that the RAAS attachment dimensions did not mediate the negative association between alexithymia and relationship satisfaction; instead, fear of intimacy and (to a lesser extent) negative affect fully explained this association. This was surprising given that alexithymia scores were significantly associated with lower scores on Close and Depend, and higher scores on Anxiety, indicating an insecure attachment style in alexithymia consistent with previous reports (Besharat et al., 2014; Lyvers et al., 2017; Thorberg et al., 2011b). Close and Depend did show the expected significant positive correlations with relationship satisfaction, whereas Anxiety showed the expected significant negative correlation; nevertheless, these indices of attachment security played no evident role in the link between alexithymia and relationship satisfaction. Results thus suggest that the low relationship satisfaction associated with alexithymia primarily reflects discomfort regarding emotional intimacy, and to a lesser degree proneness to negative affect, both of which were found to be negatively linked to relationship satisfaction in previous work as noted earlier.

Alexithymia was previously reported to be negatively associated with satisfaction in couple relationships (Besharat et al., 2014; Humphreys et al., 2009; Karakis \& Levant, 2012), a result that was replicated in the present sample. A trait defined by difficulties with identifying, describing and expressing feelings would seem to present an obvious hindrance 
to emotional sharing and emotional intimacy - interactions claimed to be crucial to satisfaction in couples (De Andrade et al., 2015; Olson \& Olson, 1999; Overall et al., 2009; Vanglelisti et al., 2002). People with alexithymia tend to misread others' emotions (Prkachin et al., 2009), which can lead to inappropriate responses, rejection, and resultant wariness when it comes to emotional intimacy. Previous research has thus reported fear of intimacy in alexithymia (Lyvers et al., 2017) as well as an insecure (anxious/avoidant) attachment style (Besharat et al., 2014; Lyvers et al., 2017; Thorberg et al., 2011b), findings which were also replicated in the present study. In addition to tying such earlier findings together, the present results emphasize the important role of fear of intimacy in the low relationship satisfaction often reported by those with alexithymia who are in a couple relationship. Given their persistent difficulties in understanding their own and their partner's feelings, the ability of an alexithymic individual to communicate their own emotional needs, and provide empathy and emotional support for their partner, are likely to be deficient, potentially leading to conflict and dissatisfaction. Bowlby's (1988) attachment theory may be relevant here, such that inadequate care from the primary caregiver during early childhood may inhibit emotional development and ultimately lead to alexithymia. Experiences of rejection and interpersonal difficulties in understanding and communicating with others may subsequently promote a fear of emotional closeness that hinders development of intimate partner bonds in couple relationships.

The findings of the present study have potential clinical implications. Given that alexithymia appears to be negatively related to relationship satisfaction via fear of intimacy and negative affect, these constructs may be fruitful treatment targets in couples therapy to improve relationship quality among those with alexithymia. More specifically, targeting beliefs related to negative moods and negative mood regulation (NMR) expectancies defined as an individual's beliefs about their ability to terminate or alleviate a negative mood 
state (see Catanzaro \& Mearns, 1990) - may be one approach to improving the ability to regulate affect and enhance emotional and interpersonal functioning. NMR expectancies have previously been linked to higher levels of distress, and alexithymia was found to be negatively associated with NMR expectancies in earlier research (Lyvers et al., 2014), providing potential support for such a therapeutic approach.

Another way of addressing both fear of intimacy and negative affect to enhance relationship quality among alexithymic individuals could be to promote a sense of positive affect via activation of the soothing-contentment system (see Gilbert, 2009, 2010; Gilbert et al., 2008). Such activation has been associated with feelings of being connected and safe in social situations (Gilbert et al., 2014; Kelly et al., 2012), and was negatively associated with stress, anxiety, and depression. Alexithymia has been reported to be negatively associated with feelings of safeness (Gilbert et al., 2012). Cultivating a sense of safety and contentment (possibly mediated by oxytocin and/or endorphins) may help improve relationship satisfaction by reducing defensiveness and negative affect. A randomized placebo controlled trial (Luminet et al., 2011) found that individuals with high alexithymia became more attuned to others' feeling states when under the influence of oxytocin, especially for negative emotions and intense expressions, whereas there was no difference from placebo in those with low or no alexithymia. As dealing with negative emotions is particularly difficult for those with alexithymia, improvement in understanding others' feelings may assist in dealing with interpersonal conflicts and difficult emotions, as well as perspective taking, to improve social bonds, interpersonal functioning, and relationship quality (Luminet et al., 2011). Further research is needed to elucidate whether self-soothing or other compassion-based techniques (e.g., Gilbert, 2010) can increase a sense of safety that can help amend alexithymic features to improve mood and reduce fear of intimacy, thereby facilitating relationship satisfaction. With regards to fear of intimacy, other research has indicated that 
directly targeting such fear can improve mood and relationship quality in couples. A study by Stanton, Campbell and Pink (2017) found that intimacy-promoting exercises were followed by improvements in self-disclosure, affection, closeness and sharing that in turn improved relationship quality and mood among people with an insecure attachment style.

The present study had several limitations. Firstly, the cross-sectional nature of the present study means that the observed relationships among variables cannot be interpreted in terms of temporal sequencing or causation, which would require the support of longitudinal data. For example, as noted earlier, evidence from longitudinal research supports bidirectional causation for the negative association of depression with relationship satisfaction (Brock et al., 2018); that is, depression worsens relationship satisfaction, and worsening relationship satisfaction increases depression. On the other hand, given the evidence for alexithymia as a stable personality trait (e.g., Thorberg et al., 2016) with likely origins in childhood experiences (Lyvers et al., 2019; Thorberg et al., 2011a), a bidirectional association of alexithymia with relationship satisfaction seems implausible. In any case the present study was not intended to establish the direction or nature of casual relationships among variables, but rather was intended only to assess whether predicted associations among variables would be present in a sample of adults in long-term couple relationships.

A more relevant limitation concerns the nature of the sample. Although each participant completed well-known, validated instruments assessing their levels of alexithymia, attachment style, fear of intimacy, and negative mood, their partner's levels of the same variables were not assessed. The characteristics of each partner in a couple relationship are likely to interact to influence relationship satisfaction in complex ways, thus assessment of the variables of the present study for both partners in couple relationships may yield informative findings in future dyadic research. 
The present findings support the notion that fear of intimacy can be a major barrier to satisfaction in romantic relationships, and may account in part (along with proneness to depression or other negative moods) for the low relationship satisfaction associated with alexithymia. The findings thus offer potentially useful information for clinicians working with couples. Although alexithymia appears to be a stable trait overall, recent research in clinical samples has indicated that targeting alexithymia with a cognitive behavioral approach can help improve some aspects of emotional awareness (Thorberg et al., 2016). Fear of intimacy is also amenable to change as noted earlier (Stanton et al., 2017), and may merit particular attention as a treatment target by clinicians when working with alexithymic clients who seek help for their relationship problems. Further research is recommended using a dyadic approach to examine the contributions of the individual characteristics examined in the present study to relationship satisfaction for both partners in long-term couple relationships.

In summary, the present study has provided some interesting findings suggesting that the negative association between alexithymia and relationship satisfaction was mediated through negative affect and even more strongly through fear of intimacy. Future studies may benefit from including a multimethod approach to assessing alexithymia in a dyadic sample and including assessments of positive emotions such as safeness, as there has been a longstanding debate in the literature as to whether those with high alexithymia can accurately identify and describe their own emotions. Including a structured interview such as the Toronto Structured Interview for Alexithymia (Bagby et al., 2006) may thus enhance the validity of alexithymia assessment and provide a more thorough and comprehensive measurement of alexithymia in relation to relationship quality. 


\section{References}

Antony, M. M., Bieling, P. J., Cox, B. J., Enns, M. W., \& Swinson, R. P. (1998).

Psychometric properties of the 42-item and 21-item versions of the Depression Anxiety Stress Scales in clinical groups and a community sample.

Psychological Assessment, 10, 176-181. doi:10.1037/1040-3590.10.2.176

Australian Bureau of Statistics (2018). Education and work, Australia, May 2018. Available: https://www.abs.gov.au/AUSSTATS/abs@.nsf/Lookup/6227.0Main+Features1May \%202018?OpenDocument

Bagby, M. R., Parker, J. D., \& Taylor, G. J. (1994). The twenty item Toronto Alexithymia Scale - I. Item selection and cross-validation of the factor structure. Journal of Psychosomatic Research, 38, 23-32. doi:10.1016/0022-3999(94)90005-1

Bagby, M. R., Taylor, G. J., \& Parker, J. D. (1994b). The twenty item Toronto Alexithymia Scale-II. Convergent, discriminant, and concurrent validity. Journal of Psychosomatic Research, 38, 33-40. doi:10.1016/0022

Bagby, R. M., Taylor, G. J., Parker, J. D., \& Dickens, S. E. (2006). The development of the Toronto Structured Interview for Alexithymia: Item selection, factor structure, reliability and concurrent validity. Psychotherapy and Psychosomatics, 75, 25-39. doi:10.1159/000089224

Bagby, R.M., Taylor, G.J., Quilty, L.C., \& Parker, J.D.A. (2007). Reexamining the factor structure of the 20-item Toronto Alexithymia Scale: Commentary on Gignac, Palmer, and Stough. Journal of Personality Assessment, 89, 258-264. doi: $10.1080 / 00223890701629771$

Besharat, M. A., Naghshineh, N., Ganji, P., \& Tavalaeyan, F. (2014). The moderating role of attachment styles on the relationship of alexithymia and fear of intimacy with marital satisfaction. International Journal of Psychological Studies, 6(3), 106-117. 
doi:10.5539/ijps.v6n3p106

Bowlby, J. (1988). A secure base: Parent-child attachment and healthy human development.

New York: Basic Books.

Brennan, K. A., Clark, C. L., \& Shaver, P. R. (1998). Self-report measurement of adult attachment: An integrative overview. In J. A. Simpson \& W. S. Rholes (Eds.), Attachment theory and close relationships (pp. 46-76). New York: Guilford.

Brock, R. L., Franz, M. R., O'Bleness, J. J. \& Lawrence, E. (2018). The dynamic interplay between satisfaction with intimate relationship functioning and daily mood in lowincome outpatients. Family Process, 36, 1-17. doi:10.1111/famp.12402

Brown, T. A., Chorpita, B. F., Korotitsch, W., \& Barlow, D. H. (1997). Psychometric properties of the Depression Anxiety Stress Scales (DASS) in clinical samples. Behavior Research and Therapy, 35, 79-89. doi:10.1016/S0005-7967(96)00068$\mathrm{X}$

Butzer, B., \& Campbell, L. (2008). Adult attachment, sexual satisfaction, and relationship satisfaction: A study of married couples. Personal Relationships, 15, 141-154. doi:10.1111/j.1475-6811.2007.00189.x

Catanzaro, S. J., \& Mearns, J. (1990). Measuring generalized expectancies for negative mood regulation: Initial scale development and implications. Journal of Personality Assessment, 54, 546-563. doi: 10.1207/s15327752jpa5403\&4_11

Cohen, J. (1992). Statistical power analysis. Current Directions in Psychological Science, 1, 98-101. doi: 10.1111/1467-8721.ep10768783

Collins, N. L. (1996). Working models of attachment. Journal of Personality and Social Psychology, 71, 810-832. doi: 10.1037/0022-3514.71.4.810

Collins, N. L., \& Read, S. J. (1990). Adult attachment, working models, and relationship 
quality in dating couples. Journal of Personality and Social Psychology, 58, 644663. doi:10.1037//0022-3514.58.4.644

De Andrade, A. L., Wachelke, J. F. R., \& Howat-Rodrigues. A. B. C. (2015).

Relationship satisfaction in young adults: Gender and love dimensions. Interpersona: An International Journal on Personal Relationships, 9, 19-31. doi:10.5964/ijpr.v9i1.157

Descutner, C. J., \& Thelen, M. H. (1991). Development and validation of a fear-of-intimacy scale. Psychological Assessment, 3, 218-225. doi:10.1037/1040-3590.3.2.218

Doi, S. C., \& Thelen, M. H. (1993). The Fear-of-Intimacy Scale: Replication and extension. Psychological Assessment, 5, 377-383. doi:10.1037/1040-3590.5.3.377

Ferguson, C. J. (2009). An effect size primer: A guide for clinicians and researchers. Professional Psychology: Research and Practice, 40, 532-538. https://doi.org/10.1037/a0015808

Fincham, F. D. (2001). Attributions and close relationships: From Balkanization to integration. In G. J. Fletcher \& M. Clark (Eds.), Blackwell handbook of social psychology (pp. 3-31). Oxford, UK: Blackwell.

Funk, J. L., \& Rogge, R. D. (2007). Testing the ruler with item response theory: Increasing precision of measurement for relationship satisfaction with the Couples Satisfaction Index. Journal of Family Psychology, 21, 572-583. doi:10.1037/0893- 3200.21.4.572

Gerlach, T.M., \& Driebe, J.C., \& Reinhard, S. (2018). Personality and romantic relationship satisfaction. In V. Zeigler-Hill \& T. Shackelford (Eds.), Encyclopedia of personality and individual differences (8 pgs.). Cham, Switzerland: Springer. doi: 10.1007/978-3319-28099-8_718-1

Gignac, G.E., Palmer, B.R., \& Stough, C. (2007). A confirmatory factor analytic 
investigation of the TAS-20: Corroboration of a five-factor model and suggestions for improvement. Journal of Personality Assessment, 89, 247-257. doi:

$10.1080 / 00223890701629730$

Gilbert, P. (2009). The compassionate mind: A new approach to the challenge of life. London: Constable \& Robinson.

Gilbert, P. (2010). Compassion Focused Therapy. London: Routledge.

Gilbert, p., McEwan, K., Mitra, R., Franks, L., Richter, A., \& Rockliff, H. (2008). Feeling safe and content: A specific affect regulation system? Relationship to depression, anxiety, stress, and self-criticism. Journal of Positive Psychology, 3, 182-191. doi: $10.1080 / 17439760801999461$

Gilbert, P., McEwan, K., Gibbons, L., Chotai, S., Duarte, J., \& Matos, M. (2012). Fears of compassion and happiness in relation to alexithymia, mindfulness, and selfcriticism. Psychology and Psychotherapy: Theory, Research and Practice, 85, 374-390. doi: 10.1111/j.2044-8341.2011.02046.x

Gilbert, P., McEwan, K., Catarino, F., Baião, R., \& Palmeira, L. (2014). Fears of happiness and compassion in relationship with depression, alexithymia, and attachment security in a depressed sample. British Journal of Clinical Psychology, 53, 228-244. doi: 10.1111/bjc.12037

Glenn, N. (1998). Problems and prospects in longitudinal research on marriage: A sociologist's perspective. In T. N. Bradbury (Ed.), The developmental course of marital dysfunction (pp. 427-440). Cambridge, UK: Cambridge University Press.

Goldman, G. A., \& Anderson, T. (2007). Quality of object relations and security of attachment as predictors of early therapeutic alliance. Journal of Counseling Psychology, 54, 111-117. doi: 10.1037/0022-0167.54.2.111

Humphreys, T. P., Wood, L. M., \& Parker, J. D. A. (2009). Alexithymia and satisfaction in 
intimate relationships. Personality and Individual Differences, 46, 43-47.

doi:10.1016/j.paid.2008.09.002

Jackson, J. B., Miller, R. B., Oka, M., \& Henry, R. G. (2014). Gender differences in marital satisfaction: A meta-analysis. Journal of Marriage and Family, 76, 105-129. doi:10.1111/jomf.12077

Jorgensen, M. M., Zachariae, R., Skytthe, A., \& Kyvik, K. (2007). Genetic and environmental factors in alexithymia: A population based study of 8,785 Danish twin pairs. Psychotherapy and Psychosomatics, 76, 369-375. doi:10.1159/000107565

Kamp Dush, C. M., Taylor, M. G., \& Kroeger, R. A. (2008). Marital happiness and psychological well-being across the life course. Family Relations, 57, 211-226. doi:10.1111/j.1741-3729.2008.00495.x

Karakis, E. N., \& Levant, R. F. (2012). Is normative male alexithymia associated with relationship satisfaction, fear of intimacy and communication quality among men in relationships? Journal of Men's Studies, 20, 179-186. doi:10.3149/jms.2003.179

Keizer. R. (2014). Relationship satisfaction. In A. C. Michalos (Ed.), Encyclopedia of quality of life and well-being research. Dordrecht, Netherlands: Springer. doi:10.1007/978-94-007-0753-5

Kelly, A. C., Zuroff, D. C., Leybman, M. J., \& Gilbert, P. (2012). Social safeness, received social support, and maladjustment: Testing a tripartite model of affect regulation. Cognitive Therapy and Research, 36, 815-826. doi:10.1007/s1068-011-9432-5

Kiecolt-Glaser, J., \& L. Newton, T. (2001). Marriage and health: His and hers. Psychological Bulletin, 127, 472-503. doi:10.1037/0033-2909.127.4.472

Kimmes, J. G., Durtschi, J. A., Clifford, C. E., Knapp, D. J., \& Fincham, F. D. (2015). The role of pessimistic attributions in the association between anxious attachment and relationship satisfaction. Family Relations, 64, 547-562. doi:10.1111/fare.12130 
Lovibond, S. H. \& Lovibond, P. F. (1995). Manual for the Depression, Anxiety and Stress Scales (2nd ed.). Sydney: Psychology Foundation.

Luminet, O., Grynberg, D., Ruzett, N., \& Mikolajczak, M. (2011). Personality-dependent effect of oxytocin. Greater social benefits for high alexithymia scorers. Biological Psychology, 87, 401-406. doi: 10.1016/j.biopsycho.2011.05.005

Luminet, O., Bagby, R. M., \& Taylor, G. J. (2018). Alexithymia: Advances in research, theory, and clinical practice. Cambridge, UK: Cambridge University Press.

Lyvers, M., Davis, S., Edwards, M.S., \& Thorberg, F.A. (2017). Alexithymia, fear of intimacy and attachment in young adults. IAFOR Journal of Psychology \& Behavioral Sciences, 3, 1-11. doi: 10.22492/ijpbs.3.2.01

Lyvers, M., Kohlsdorf, S., Edwards, M., \& Thorberg, F. (2017). Alexithymia and mood: Recognition of emotion in self and others. American Journal of Psychology, 130, 8392. doi:10.5406/amerjpsyc.130.1.0083

Lyvers, M., Mayer, K., Needham, K., \& Thorberg, F.A. (2019). Parental bonding, adult attachment, and theory of mind: A developmental model of alexithymia and alcoholrelated risk. Journal of Clinical Psychology, 75, 1288-1304. doi: 10.1002/jclp.22772

Lyvers, M., McCann, K., Coundouris, S., Edwards, M.S., \& Thorberg, F.A. (2018).

Alexithymia in relation to alcohol use, emotion recognition and empathy: The role of externally oriented thinking. American Journal of Psychology, 131, 41-51. doi:

10.5406/amerjpsyc.131.1.0041

Lyvers, M., Makin, C., Toms, E., Thorberg, F.A., \& Samios. C. (2014). Trait mindfulness in relation to emotional self-regulation and executive function. Mindfulness, 5, 619625. doi: 10.1007/s12671-013-0213-y

Mattila, A.K., Salminen, J.K., Nummi, T., \& Joukamaa, M. (2006). Age is strongly 
associated with alexithymia in the general population. Journal of Psychosomatic Research, 61, 629-635. doi: 10.1016/j.jpsychores.2006.04.013

McGillivray, L., Becerra, R., \& Harms, C. (2016). Prevalence and demographic correlates of alexithymia: A comparison between Australian psychiatric and community samples. Journal of Clinical Psychology, 73(1), 76-87. doi: 10.1002/jclp.22314

Meganck, R., Vanheule, S., \& Desmet, M. (2008). Factorial validity and measurement invariance of the 20-item Toronto Alexithymia Scale in clinical and nonclinical samples. Assessment, 15, 36-47. doi: 10.1177/1073191107306140

Mikulincer, M., \& Shaver, P. R. (2007). Attachment processes and couple functioning. In M. Mikulincer \& P. R. Shaver (Eds.), Attachment in adulthood: Structure, dynamics, and change (pp. 285-325). New York; Guilford Press.

Mikulincer, M., Shaver, P. R., \& Pereg, D. (2003). Attachment theory and affect regulation: The dynamics, development, and cognitive consequences of attachment-related strategies. Motivation and Emotion, 27(2), 77-102. https://doi.org/10.1023/A:1024515519160

Olson, D. H., \& Olson, A. K. (1999). PREPARE/ENRICH Program: Version 2000. In R. Berger \& M. T. Hannah (Eds.), Preventive approaches in couples therapy (pp. 196216). Philadelphia, PA, US: Brunner/Mazel.

Overall, N. C., Fletcher, G. J. O., Simpson, J. A., \& Sibley, C G. (2009). Regulating partners in intimate relationships: The costs and benefits of different communication strategies. Journal of Personality and Social Psychology, 96, 620-639. doi:10.1037/a0012961

Patrick, S., Sells, J.N., Giordano, F.G., \& Tollerud, T.R. (2007). Intimacy, differentiation, and personality variables as predictors of marital satisfaction. Family Journal, 15, 359-367. doi: 10.1177/1066480707303754 
Preece, D., Becerra, R., Allan, A., Robinson, K., \& Dandy, J. (2017). Establishing the theoretical components of alexithymia via factor analysis: Introduction and validation of the attention-appraisal model of alexithymia. Personality and Individual Differences, 119, 341-352. doi: 10.1016/j.paid.2017.08.003

Prkachin, G. C., Casey, C., \& Prkachin, K. M. (2009). Alexithymia and perception of facial expressions of emotion. Personality and Individual Differences, 46, 412-417. doi:10.1016/j.paid.2008.11.010

Qualter, P., Quinton, S.J., Wagner, H., \& Brown, S. (2009). Loneliness, interpersonal distrust, and alexithymia in university students. Journal of Applied Social Psychology, 39, 61461-1479. doi: 1559-1816.2009.00491.x

Rosand, G. M., Slinning, K., Eberhard-Gran, M., Roysamb, E., \& Tambs, K. (2012). The buffering effect of relationship satisfaction on emotional distress in couples. $B M C$ Public Health, 12, 1-13. doi:10.1186/1471-2458-12-66

Salminen, J.K., Saarijärvi, S., Äärelä, E., Toikka, T., \& Kauhanen, J. (1999). Prevalence of alexithymia and its association with sociodemographic variables in the general population of Finland. Journal of Psychosomatic Research, 46, 75-82. doi: 10.1016/S0022-3999(98)00053-1.

Schaffhuser, K., Allemand, M., \& Martin, M. (2014). Personality traits and relationship satisfaction in intimate couples: Three perspectives on personality. European Journal of Personality, 28, 120-133. doi:10.1002/per.1948

Sekely, A., Bagby, R. M., \& Porcelli, P. (2018). Assessment of the alexithymia construct. In O. Luminet, R. M. Bagby \& G. J. Taylor (Eds.), Alexithymia: Advances in research, theory, and clinical practice (pp. 17-32). Cambridge, UK: Cambridge University Press. doi: 10.1017/9781108241595.004 
Spitzer, C., Siebel-Jurges, U., Barnow, S., Grabe, H., \& Freyberger, H. (2005). Alexithymia and interpersonal problems. Psychotherapy and Psychosomatics, 74, 240-246. doi:10.1159/000085148

Stanton, S., Campbell, L., \& Pink, J. (2017). Benefits of positive relationship experiences for avoidantly attached individuals. Journal of Personality and Social Psychology, 113, 568-588. doi: 10.1037/pspi0000098

Tabachnick, B. G., \& Fidell, L. S. (2013). Using multivariate statistics (6th ed.). Boston, MA: Pearson.

Taylor., G. J., \& Bagby., R. M. (2004). New trends in alexithymia research. Psychotherapy and Psychosomatics, 73, 68-77. doi: 10.1159/000075537

Thelen, M. H., Vander Wal, J. S., Thomas, A. M., \& Harmon, R. (2000). Fear of intimacy among dating couples. Behavior Modification, 24, 223-240. doi:10.1177/0145445500242004

Thorberg, F. A., Young, R. M., Sullivan, K. A., \& Lyvers, M. (2009). Alexithymia and alcohol use disorders: A critical review. Addictive Behaviors, 34, 237-245. doi: 10.1016/j.addbeh.2008.10.016

Thorberg, F.A., Young, R., Sullivan, K.A., \& Lyvers, M. (2011a). Parental bonding and alexithymia: A meta-analysis. European Psychiatry, 26, 187-193. doi: 10.1016/j.eurpsy.2010.09.010

Thorberg, F. A., Young, R. M., Sullivan, K. A., Lyvers, M., Connor, J. P. \& Feeney, G. F. (2011b). Attachment security and alexithymia in a heavy drinking sample. Addiction Research and Theory, 19, 566-570. doi:10.3109/16066359.2011.580065

Thorberg, F. A., Young, R. McD., Sullivan, K. A., Lyvers, M., Connor, J. P., \& Feeney, GFX. (2010). A psychometric comparison of the Toronto Alexithymia Scale (TAS- 
20) and the Observer Alexithymia Scale (OAS) in an alcohol dependent sample. Personality \& Individual Differences, 49, 119-123. doi: 10.1016/j.paid.2010.03.018

Thorberg, F.A., Young, R.M., Sullivan, K.A., Lyvers, M., Hurst, C.P., Connor, J.P., Tyssen, R., London, E.D., Noble, E.P. \& Feeney, G.F.X. (2016). A longitudinal mediational study on the stability of alexithymia among alcohol-dependent outpatients in Cognitive-Behavioral Therapy. Psychology of Addictive Behaviors, 30, 64-72. doi: 10.1037/adb000013530

Vanglelisti, A. L., Reis, H. T., \& Fitzpatrick, M. A. (2002). Stability and change in relationships. New York: Cambridge University Press.

Vollmann, M., Sprang, S., van den Brink, F. (2019). Adult attachment and relationship satisfaction: The mediating role of gratitude toward the partner. Journal of Social and Personal Relationships, 36, 3875-3886. doi: 10.1177/0265407519841712

Yoo, H., Bartle-Haring, S., Day, R.D., \& Gangamma, R. (2014). Couple communication, emotional and sexual intimacy, and relationship satisfaction. Journal of Sex and Marital Therapy, 40, 275-293. doi:10.1080/0092623X.2012.751072

Zech, E., Luminet, B. Rime, \& H. Wagner (1999). Alexithymia and its measurement: Confirmatory factor analyses of the 20-item Toronto Alexithymia Scale and the Bermond-Vorst Alexithymia Questionnaire. European Journal of Personality, 13, 511-532. doi: 10.1002/(SICI)1099-0984(199911/12)13:6<51

Zhang, F., \& Labouvie-Vief, G. (2004). Stability and fluctuation in adult attachment style over a 6-year period. Attachment \& Human Development, 6, 419-437. doi:10.1080/1461673042000303127 
Alexithymia and relationships

Table 1. Means, standard deviations, and range of study variables $(N=158)$

\begin{tabular}{lcc} 
Variable & $M(S D)$ & Range \\
\hline 1. Couples Satisfaction & $69.70(13.80)$ & $15-93$
\end{tabular}

2. Alexithymia $\quad 58.22(12.22) \quad 24-80$

3. RAAS-Close $3.18(.72) \quad 1-5$

4. RAAS-Depend $2.78(.79) \quad 1-5$

5. RAAS-Anxiety $\quad 3.18(1.00) \quad 1-5$

6. Fear of Intimacy $94.61(22.26) \quad 45-143$

7. Negative Mood $49.06(34.04) \quad 0-126$

8. Age (yr) $28.84(6.43) \quad 18-40$

9. Relationship Length (yr) $\quad 5.53(4.48) \quad 1-19$

Note. RAAS $=$ Revised Adult Attachment Scale. 
Table 2. Intercorrelations of study variables $(N=158)$

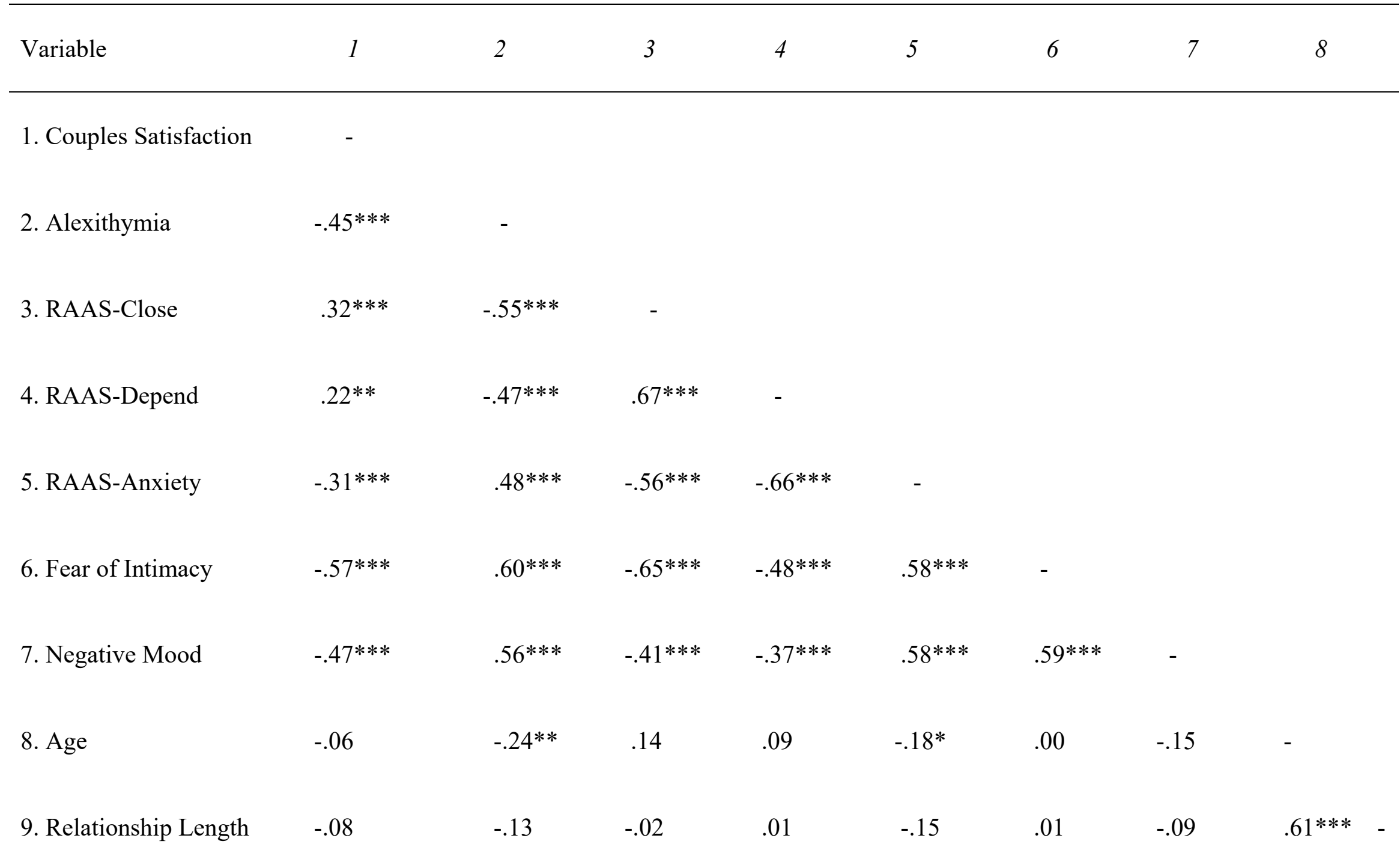

Note. $\mathrm{RAAS}=$ Revised Adult Attachment Scale. ${ }^{*} p<.05 .{ }^{* *} p<.01 .{ }^{* * *} p<.0001$.

This is the peer reviewed version of the following article: Lyvers, M., Pickett, L., Needham, K., \& Thorberg, F. A. (2021). Alexithymia, Fear of Intimacy, and Relationship Satisfaction. Journal of Family Issues. https://doi.org/10.1177/0192513X211010206 
Table 3. Direct and indirect effects of TAS-20 alexithymia on CSI relationship satisfaction with mediation by FIS fear of intimacy and DASS-21 negative affect, controlling for age, sex, relationship type, and relationship length. AAS attachment dimensions Close, Depend, and Anxiety showed no evidence of mediation.

Direct effects

\begin{tabular}{lrrrrrrr}
\hline & & & & & \multicolumn{2}{c}{$95 \%$ Confidence Interval } \\
\cline { 6 - 8 } & & Estimate & Std. Error & z-value & $\mathrm{p}$ & Lower & Upper \\
\hline TAS20 & $\rightarrow$ CSI & -0.182 & 0.085 & -2.131 & 0.033 & -0.382 & 0.011 \\
\hline
\end{tabular}

Note. Delta method standard errors, bias-corrected percentile bootstrap confidence intervals, ML estimator.

Indirect effects

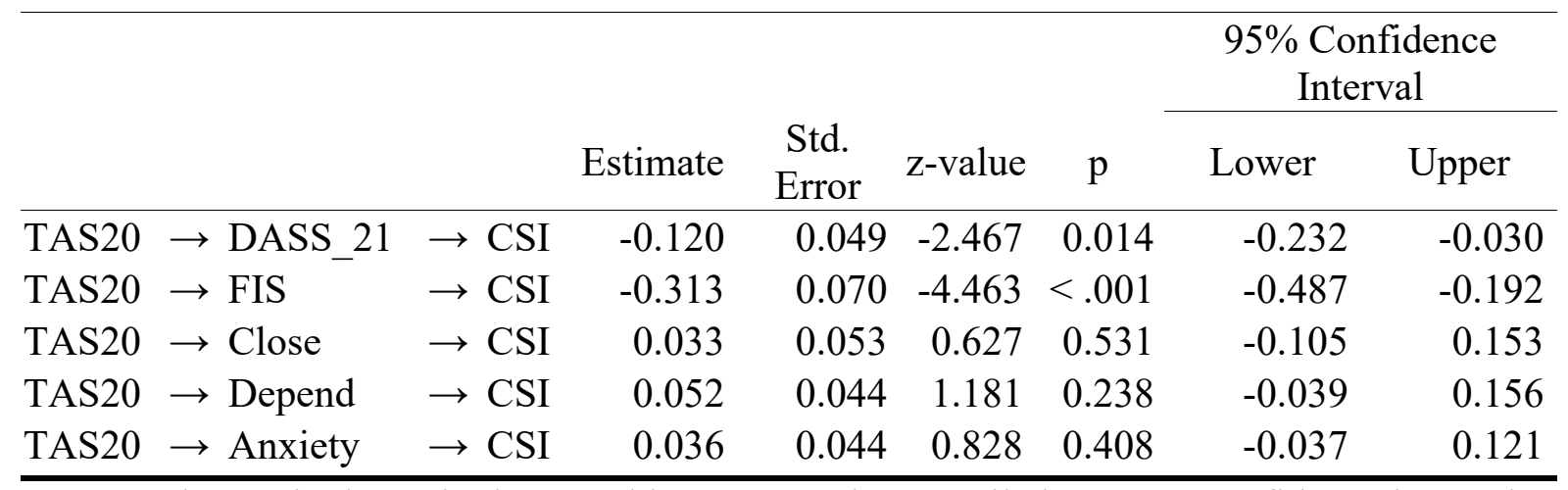

Note. Delta method standard errors, bias-corrected percentile bootstrap confidence intervals, ML estimator.

Total effects

\begin{tabular}{ccrrrrrr}
\hline & & & & & \multicolumn{3}{c}{$95 \%$ Confidence Interval } \\
\cline { 7 - 9 } & & Estimate & Std. Error & z-value & $\mathrm{p}$ & Lower & Upper \\
\hline TAS20 & $\rightarrow$ CSI & -0.494 & 0.072 & -6.887 & $<.001$ & -0.663 & -0.355 \\
\hline
\end{tabular}

Note. Delta method standard errors, bias-corrected percentile bootstrap confidence intervals, ML estimator.

Total indirect effects

\begin{tabular}{lrrrrrrr}
\hline & & & & & \multicolumn{3}{c}{$95 \%$ Confidence Interval } \\
\cline { 7 - 9 } & & Estimate & Std. Error & z-value & $\mathrm{p}$ & Lower & Upper \\
\hline TAS20 $\rightarrow$ CSI & -0.312 & 0.068 & -4.582 & $<.001$ & -0.447 & -0.198 \\
\hline
\end{tabular}

Note. Delta method standard errors, bias-corrected percentile bootstrap confidence intervals, ML estimator. 
Figure 1. Full mediation of the negative association between alexithymia and relationship satisfaction by fear of intimacy and negative affect, controlling for age, sex, relationship type, and relationship length. Attachment dimensions (Close, Depend, Anxiety) showed no evidence of mediation.

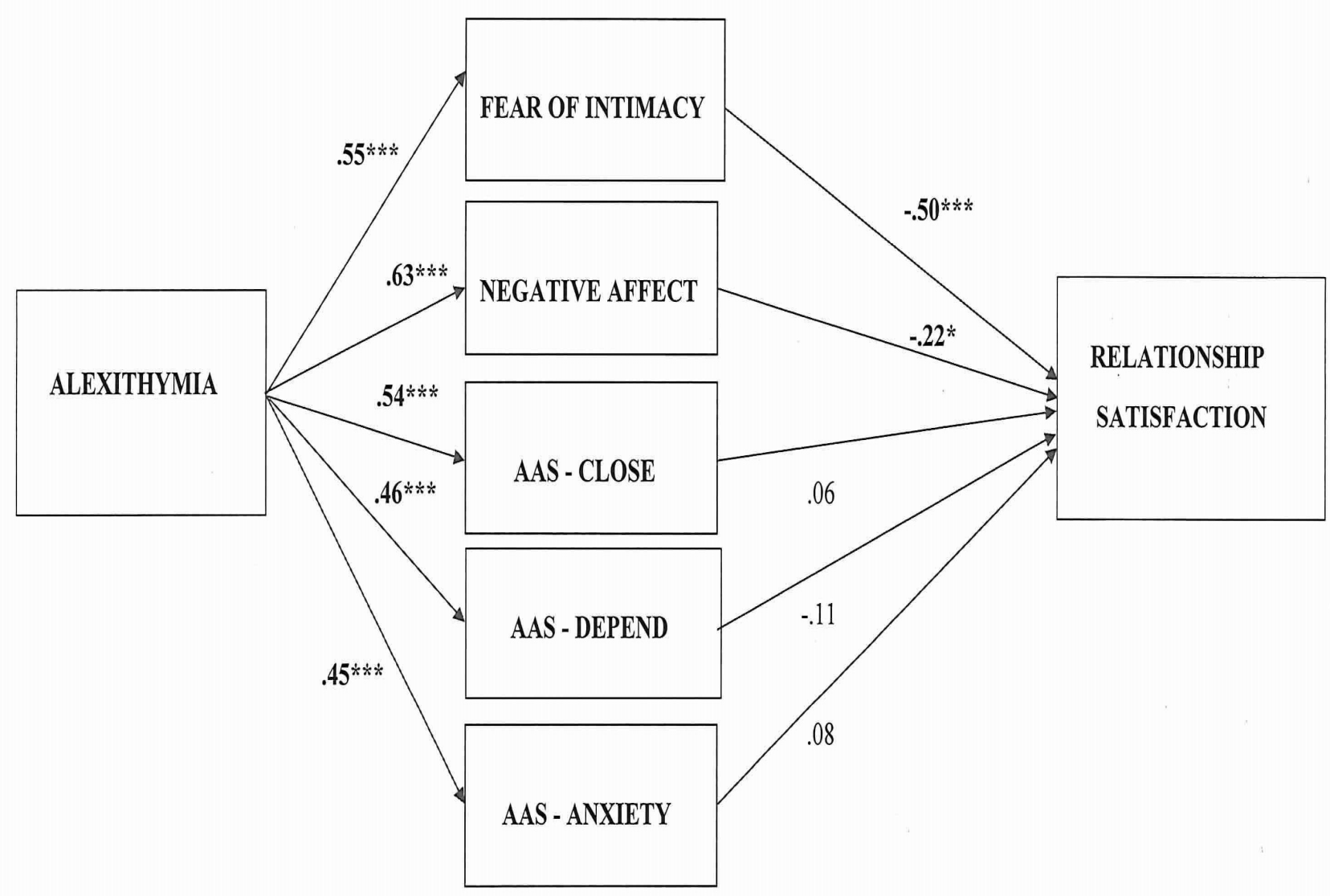

